LEMBAR

HASIL PENILAIAN SEJAWAT SEBIDANG ATAU PEER REVIEW KARYA ILMIAH : JURNAL ILMIAH

Judul Jurnal Ilmiah (Artikel)

Penulis Jurnal Ilmiah

Jumlah penulis

Status Pengusul

Identitas Jurnal Ilmiah
: Experimental Studies on a Solar Air Heater Having V-Corrugated Absorber Plate with Obstacles Bent Vertically

: Ekadewi A. Handoyo, Djatmiko Ichsani, Prabowo, Sutardi

: 3 orang

: penulis pertama / penulis ke / penulis kerespendensi
a. Nama Jurnal
: Applied Mechanics and Materials
b. Nomor ISSN
: $1662-7482$
c. Vol.,no.,bulan,tahun : Vol 493, Januari 2014
d. Penerbit
e. DOI artikel
: Trans Tech Publications
https://doi.org/10.4028/www.scientific.net/AMM.493.86
f. Alamat web jurnal :
https://www.scientific.net/AMM.493.86
http://repository.petra.ac.id/id/eprint/18315

g. Terindeks di

: terindeks scopus dan SJR 0.1492014 Q3

Kategori Publikasi Jurnal Ilmiah : $\quad$ Jurnal Ilmiah Internasional / internasional bereputasi

(beri $\checkmark$ pada kategori yang tepat)

\title{
Jurnal Ilmiah Nasional Terakreditasi
} Jurnal Ilmiah Nasional Tidak Terakreditasi

Hasil Penilaian Peer Review :

\begin{tabular}{|c|c|c|c|c|}
\hline \multirow[b]{2}{*}{$\begin{array}{l}\text { Komponen } \\
\text { Yang Dinilai }\end{array}$} & \multicolumn{3}{|c|}{ Nilai Maksimal Jurnal Ilmiah 40 x $60 \%$} & \multirow[b]{2}{*}{$\begin{array}{c}\text { Nilai Akhir } \\
\text { Yang } \\
\text { Diperoleh }\end{array}$} \\
\hline & Internasional & $\begin{array}{c}\text { Nasional } \\
\text { Terakreditasi }\end{array}$ & $\begin{array}{c}\text { Nasional } \\
\text { Tidak } \\
\text { Terakreditasi }\end{array}$ & \\
\hline a. Kelengkapan unsur isi artikel (10\%) & 2.4 & & & 2,0 \\
\hline $\begin{array}{l}\text { b. Ruang lingkup dan kedalaman } \\
\text { pembahasan }(30 \%)\end{array}$ & 7.2 & & & 7,0 \\
\hline $\begin{array}{l}\text { c. Kecukupan dan kemutahiran } \\
\text { data/informasi dan metodologi }(30 \%)\end{array}$ & 7.2 & & & 7,0 \\
\hline $\begin{array}{l}\text { d. Kelengkapan unsur dan kualitas } \\
\text { terbitan/jurnal }(30 \%)\end{array}$ & 7.2 & & & 4,0 \\
\hline Total $=(100 \%)$ & 24 & & & \\
\hline Nilai Pengusul $=$ & & & & 20,0 \\
\hline
\end{tabular}

Catatan Penilaian artikel oleh Reviewer :

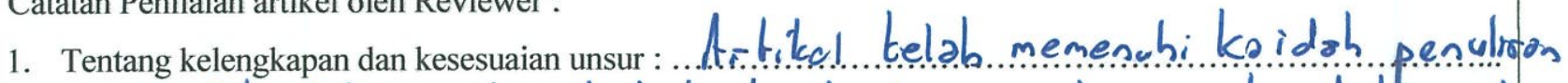

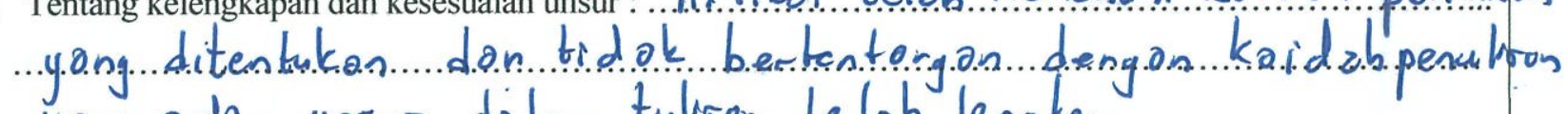

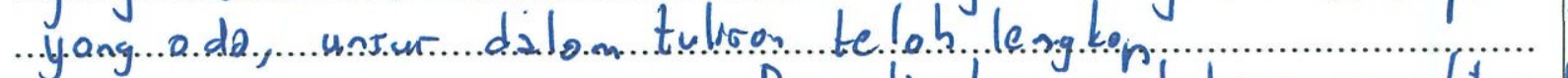

2. Tentang ruang lingkup \& kedalaman pembahasan : Ru any lingleyp pen bohoon spess. fik podo

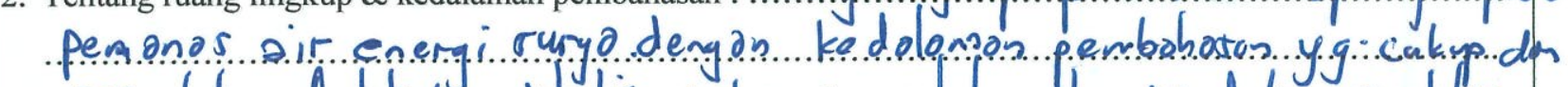

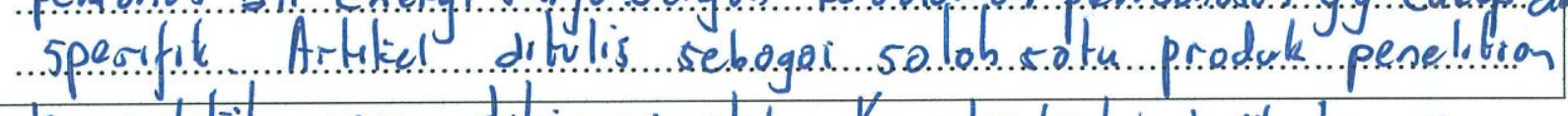
kompetitij yang dibiayai oleh Kopertor Wilay oh vil Jawo Timur. 
3. Kecukupan dan kemutahiran data serta metodologi : Mr.tode....y.ong...digusaleas men.o.d.a. untul

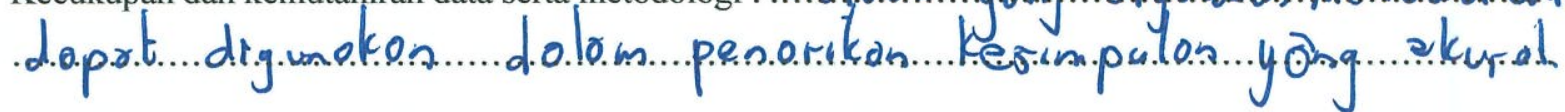

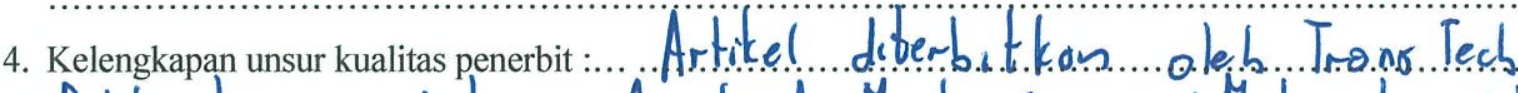

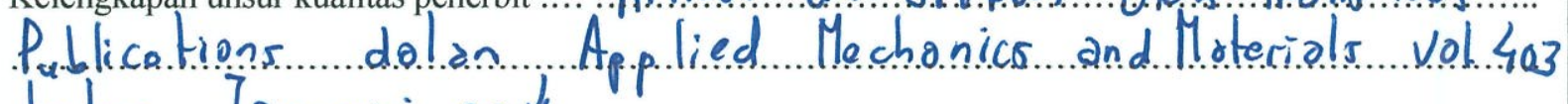

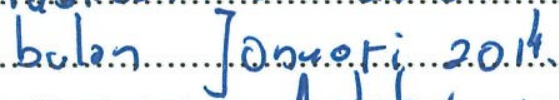

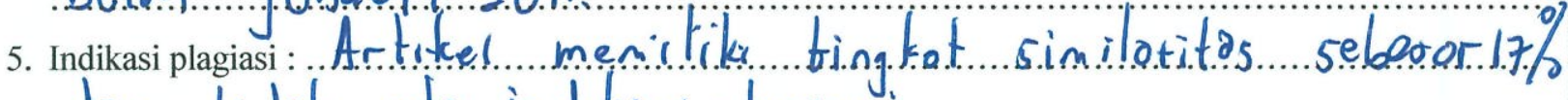

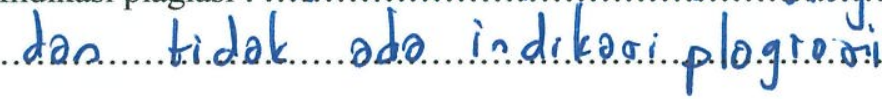

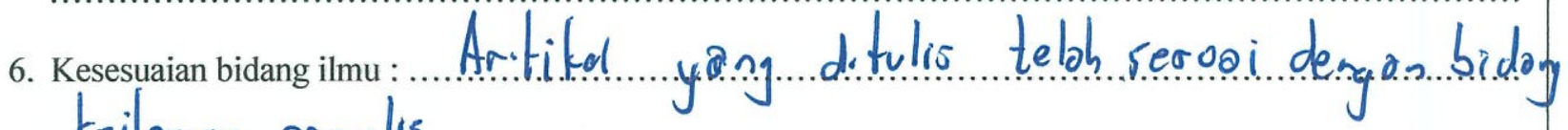
keilms on ...pen.r.lis.

Surakarto 26 Februori.2021 Reviewer

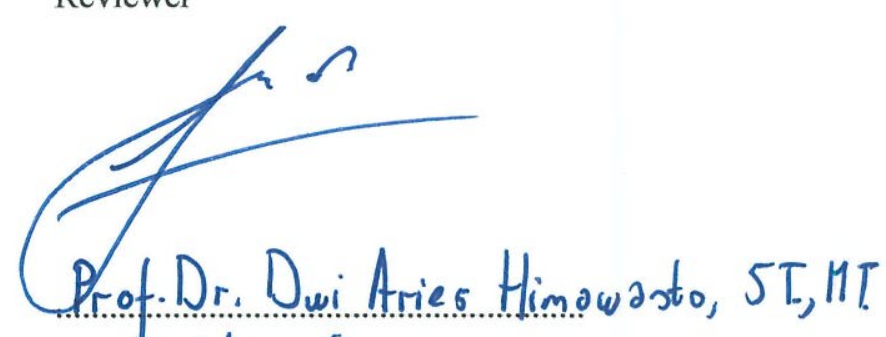
NIP . 1974 o 326 2 2000031001 Unit kerja: Univi....5ebe!. . Mared Jbt. Akademik : .Guru...Bar.o.r... Bidang Ilmu : ......Tetrouk...Merin.

(2) 12,8 


\section{LEMBAR \\ HASIL PENILAIAN SEJAWAT SEBIDANG ATAU PEER REVIEW \\ KARYA ILMIAH : JURNAL ILMIAH}

Judul Jurnal Ilmiah (Artikel)

Penulis Jurnal Ilmiah

Jumlah penulis

Status Pengusul

Identitas Jurnal Ilmiah
Experimental Studies on a Solar Air Heater Having V-Corrugated Absorber Plate with Obstacles Bent Vertically

Ekadewi A. Handoyo, Djatmiko Ichsani, Prabowo, Sutardi

\section{3 orang}

penulis pertama / penuliske / penulis kerespondensi
a. Nama Jurnal
Applied Mechanics and Materials
b. Nomor ISSN
$1662-7482$
c. Vol.,no.,bulan,tahun
Vol 493, Januari 2014
d. Penerbit
Trans Tech Publications
e. DOI artikel
https://doi.org/10.4028/www. scientific.net/AMM.493.86
f. Alamat web jurnal
https://www.scientific.net/AMM.493.86
http://repository.petra.ac.id/id/eprint/18315

g. Terindeks di

terindeks scopus dan SJR 0.1492014 Q3

Kategori Publikasi Jurnal Ilmiah (beri $\checkmark$ pada kategori yang tepat)

$\square$ Jurnal Ilmiah Internasional / internasional bereputasi

Hasil Penilaian Peer Review :

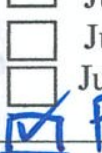
Jurnal Ilmiah Nasional Terakreditasi

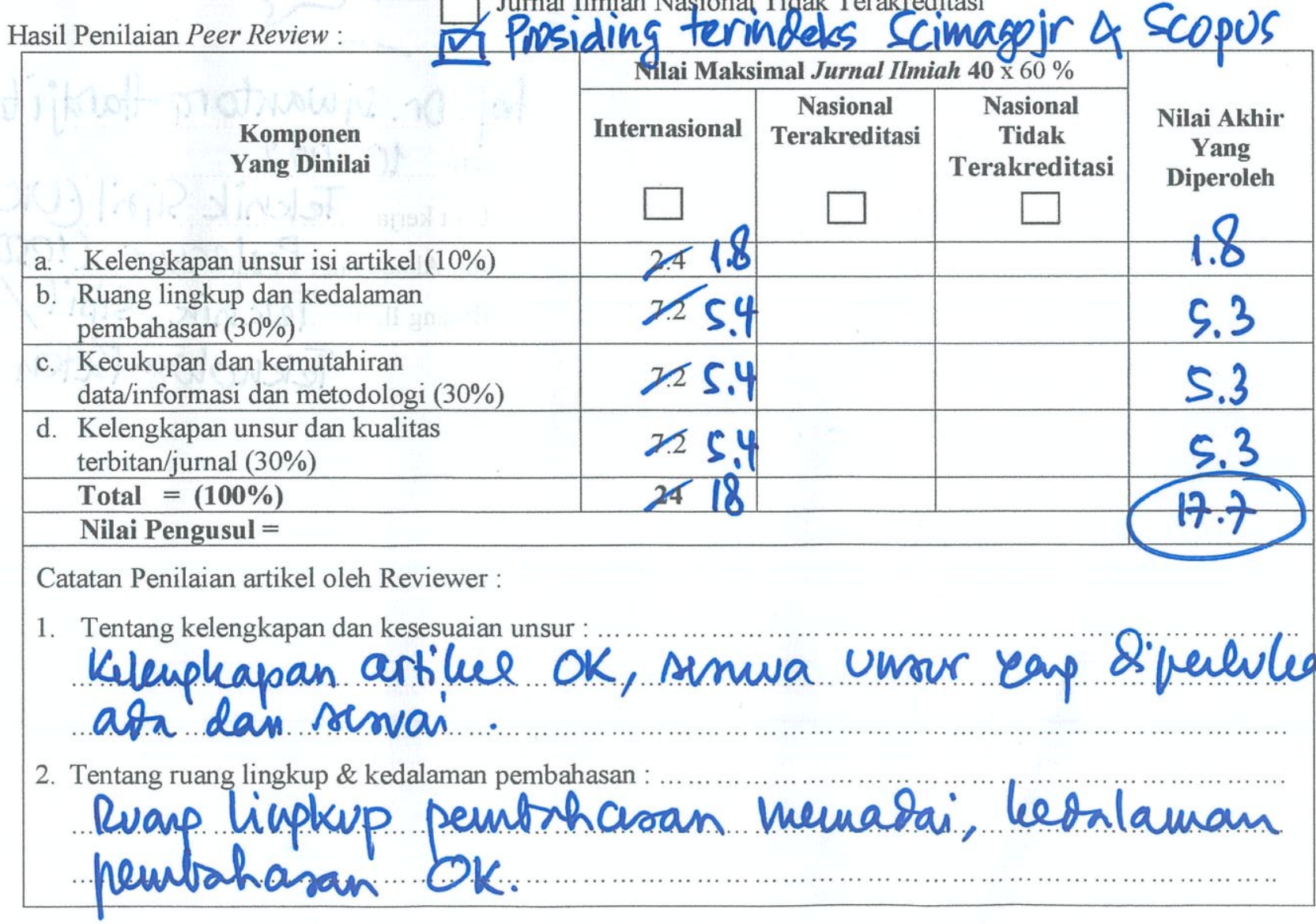


3. Kecukupan dan kemutahiran data serta metodologi :

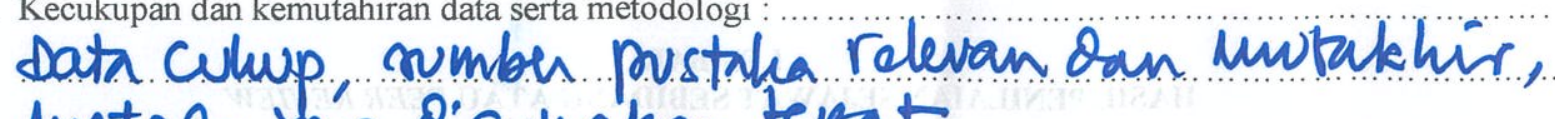

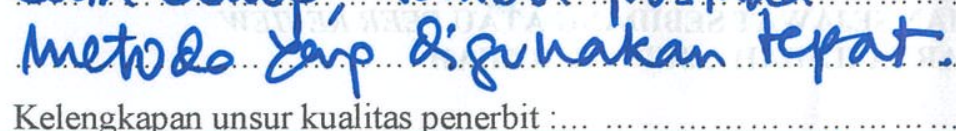

Kelengleapan unsur Wualitan benerit OK. Terindeles d Scopus dentara 2005-2015, STR (2014) = 0.149

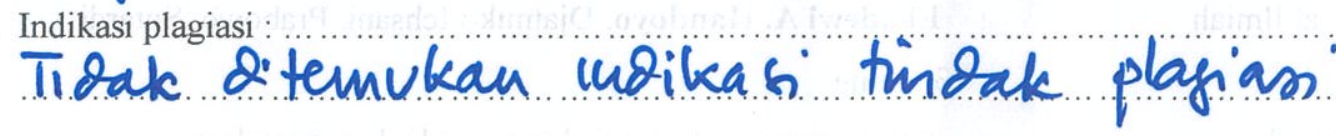

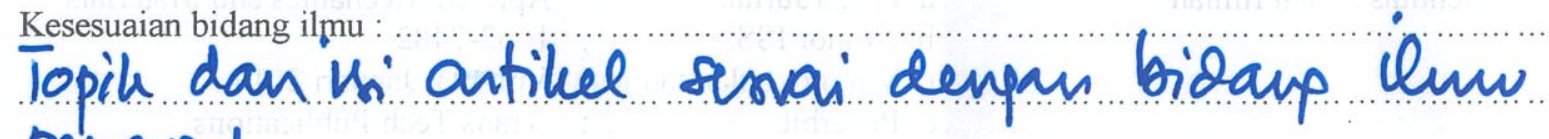
pengusul.

Surabaya, $25-1-2021$

Qher

$\operatorname{Pr}$ f.. Dr. Djwantoro Hardjito, M.Eng NIP $10-002$

Unit kerja Teknik Sipil (UK Petra)

Jbt. Akademik: Prifessor (1050).

Bidang Ilmu : Teknik Sipil

Teknologi Beton. 